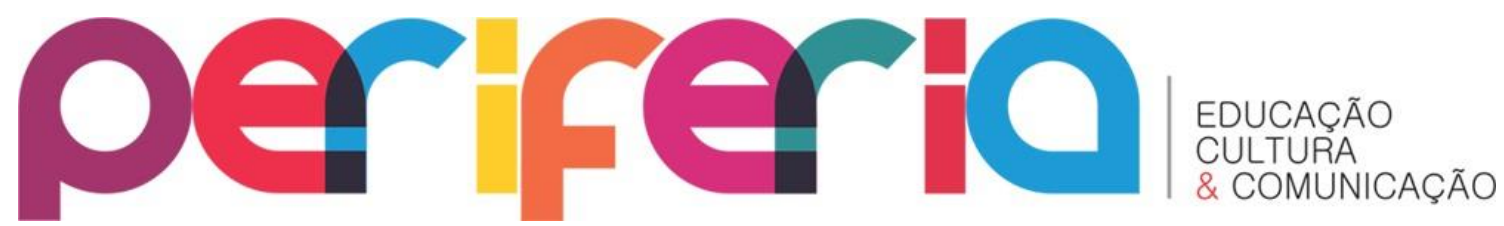

\title{
POLÍTICAS PÚBLICAS DE POPULARIZAÇÃO DA CIÊNCIA E MOVIMENTOS ANTICIENTIFICISTAS NO BRASIL: UMA ANÁLISE DISCURSIVA
}

\author{
Gustavo Diniz de Mesquita Taveira ${ }^{1}$ \\ Gabriela da Silva Carneiro ${ }^{2}$ \\ Guilherme Pereira Stribel ${ }^{3}$
}

\section{Resumo}

0 presente trabalho busca refletir sobre as relações entre o aumento de políticas públicas de popularização da ciência e os posicionamentos anticientificistas. Em um primeiro momento, são apresentadas diversas políticas públicas que, principalmente desde 2003, ampliaram o alcance da ciência na sociedade brasileira. Paralelamente, evidencia-se o crescimento do movimento anticientificista no Brasil, apresentado como um problema social grave, oriundo de disputas hegemônicas, que implicam, por exemplo, no ressurgimento de doenças já controladas. Em uma perspectiva discursiva, este artigo articular-se com a ideia de não reduzir tais movimentos a farsa e sim, tentar compreender suas redes de formações discursivas. Leva-se em consideração que estes movimentos também se fazem presentes no âmbito educacional; logo, a educação é discutida em diferentes conjecturas, segundo a proposta de Gohn, a saber, educação formal, educação não-formal, e educação informal. A partir destas três categorias, reflete-se sobre a produção curricular como arena de disputa de sentidos, compreendendo que a popularização da ciência está atravessada/atravessa todos estes campos educacionais.

PALAVRAS-CHAVE: divulgação científica, anticientificismo, currículo, discurso

\footnotetext{
${ }^{1}$ Mestre em Biociências pela Universidade do Estado do Rio de Janeiro e doutorando pelo Programa de Pós-graduação em Química Biológica (Educação, Gestão e Difusão em Biociências) da Universidade Federal do Rio de Janeiro e graduado em Licenciatura em Ciências Biológicas pela UERJ. Professor do Ensino Básico e Coordenador Técnico de Ciências Naturais na Secretaria Municipal de Educação de Mangaratiba. E-mail: taveiragdm@gmail.com. ORCID iD: https: / / orcid.org/0000-0002-0959-3143.

${ }^{2}$ Graduanda em Ciências Biológicas, modalidade Licenciatura, na Universidade Federal do Rio de Janeiro. Realiza Iniciação Científica no Laboratório de Biologia Molecular e Bioquímica de Proteínas. E-mail: gabrielacarneiro99@gmail.com. ORCID iD: https://orcid.org/0000-00031895-4614.

3 Doutor em Educação pelo Programa de Pós-Graduação em Educação (ProPEd - UERJ), Mestre em Educação, Cultura e Comunicação, pela Faculdade de Educação da Baixada Fluminense/UERJ. Licenciado em Geografia pela UERJ. Professor da Universidade Estácio de Sá. E-mail: guilhermenpereira@gmail.com. ORCID iD: https://orcid.org/0000-0002-5633-4670.
} 


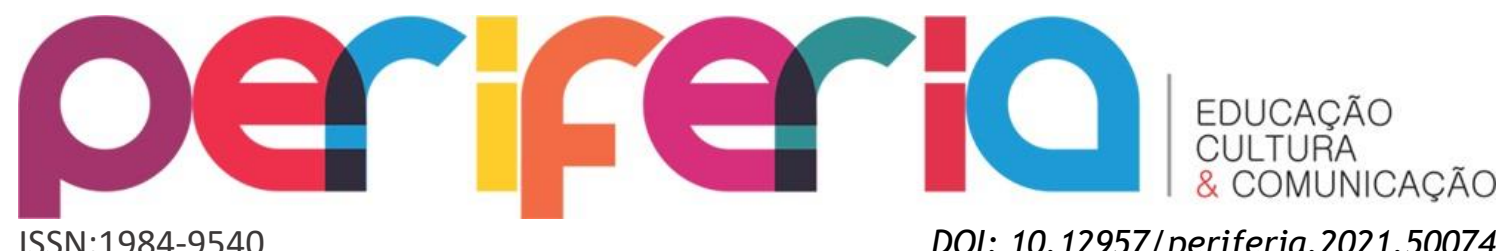

ISSN:1984-9540

DOI: $10.12957 /$ periferia.2021.50074

PUBLIC POLICIES FOR POPULARIZATION OF SCIENCE AND ANTISCIENTIFIC MOVEMENTS IN BRAZIL: A DISCURSIVE ANALYSIS

\begin{abstract}
This paper seeks to reflect on the relationship between the increase in public policies for the popularization of science and anti-scientific positions. At first, several public policies are presented that, especially since 2003, have expanded the reach of science in Brazilian society. At the same time, the growth of the anti-scientific movement in Brazil is evidenced, presented as a serious social problem, arising from hegemonic disputes, which implies, for example, the resurgence of already controlled diseases. In a discursive perspective, this article articulates with the idea of not reducing such movements to farce, but rather, trying to understand their discursive training networks. It is taken into account that these movements are also present in the educational scope; therefore, education is discussed in different conjectures, according to Gohn's proposal, namely, formal education, non-formal education, and informal education. From these three categories, it is reflected on the curricular production as arena of dispute of meanings, understanding that the popularization of science is crossed / crosses all these educational fields.
\end{abstract}

Keywords: scientific dissemination, anti-scientificism, curriculum, discourse

\title{
POLÍTICAS PÚBLICAS PARA LA POBLARIZACIÓN DE LA CIENCIA Y LOS MOVIMIENTOS ANTICIENTÍFICOS EN BRASIL: UN ANÁLISIS DISCURSIVO
}

\section{Resumen}

Este artículo busca reflexionar sobre la relación entre el aumento de las políticas públicas para la popularización de la ciencia y las posiciones anticientíficas. Al principio, se presentan varias políticas públicas que, especialmente desde 2003, han ampliado el alcance de la ciencia en la sociedad brasileña. Al mismo tiempo, se evidencia el crecimiento del movimiento anticientífico en Brasil, presentado como un problema social grave, derivado de disputas hegemónicas, lo que implica, por ejemplo, el resurgimiento de enfermedades ya controladas. Desde una perspectiva discursiva, este artículo se articula con la idea de no reducir tales movimientos a la farsa, sino de tratar de comprender sus redes de entrenamiento discursivo. Se tiene en cuenta que estos movimientos también están presentes en el ámbito educativo; por lo tanto, la educación se discute en diferentes conjeturas, de acuerdo con la propuesta de Gohn, a saber, educación formal, educación no formal y educación informal. A partir de estas tres categorías, se refleja en la producción curricular como arena de disputa de significados, entendiendo que la popularización de la ciencia se cruza / cruza todos estos campos educativos.

PALABRAS CLAVE: difusión científica, anticientífico, currículum, discurso. 


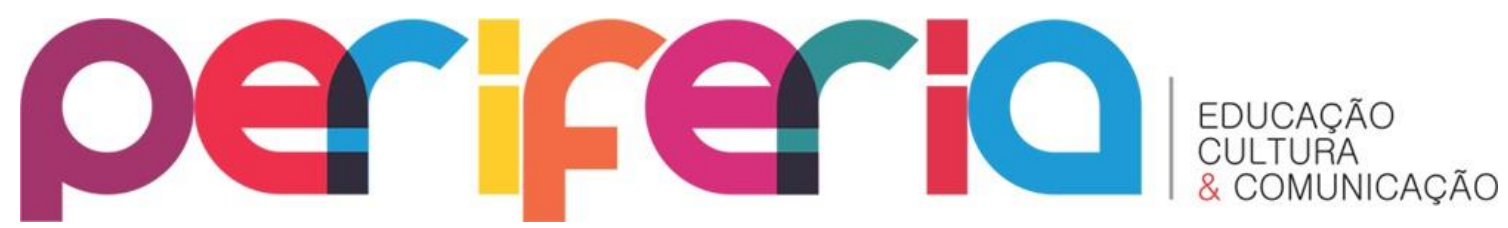

\section{Divulgação científica no Brasil}

Em perspectiva histórica, desde a década de 1980, a comunidade científica tem se mobilizado e operado ações de popularização da ciência no Brasil. No referido período foram criados 31 centros e museus de ciências (63\% a mais que a década anterior), entre eles o Espaço Ciência Viva (Rio de Janeiro/RJ, 1983) e a Estação Ciência (São Paulo/SP, 1987) (BRITO; FERREIRA; MASSARANI, 2009, p.126). Além disso, foram criadas revistas de divulgação científica, como a Ciência Hoje (1982) e a Superinteressante (1987). Nesse ínterim, emergem seções de ciência em jornais diários, como A Folha de São Paulo e O Globo. Os anos de 1990 foram ainda mais decisivos, com a implantação de mais 45 museus de ciência, como o Espaço Ciência (Recife/PE, 1995) e a Casa da Ciência da UFRJ (Rio de Janeiro/RJ, 1995). Diversas Olimpíadas Científicas, direcionadas, majoritariamente, aos alunos de Anos Finais do Ensino Fundamental e de Ensino Médio, também foram criadas (FERREIRA, 2014).

Apesar destas iniciativas importantes de promoção da popularização científica desde a década de 1980, não existia, no Brasil, uma política nacional unificadora dessas ações. Segundo Ferreira (2014), somente a partir de 2003, no governo do então presidente eleito Luiz Inácio Lula da Silva, verificou-se a existência de um contexto político-institucional favorável ao fortalecimento do papel do Estado, podendo, assim, dar início às políticas públicas de caráter nacional para a popularização da ciência.

Em sua pesquisa, Ferreira ressalta falas como a de Fonseca (2009, p.10), que admite "mudanças nas formas históricas de Estado e de administração e no pacto político a partir do início do governo do presidente Lula", sugerindo o acréscimo do termo "social" à classificação do Estado Liberal-Dependente que estava em vigor. Além disso, Sader (2003, p.138) caracteriza uma quebra com o modelo neoliberal, (alimentado por Fernando Collor de Mello, Itamar Franco e Fernando Henrique (ardoso) tais como a priorização de políticas sociais e não o ajuste fiscal, dos processos de integração regional e dos intercâmbios com 


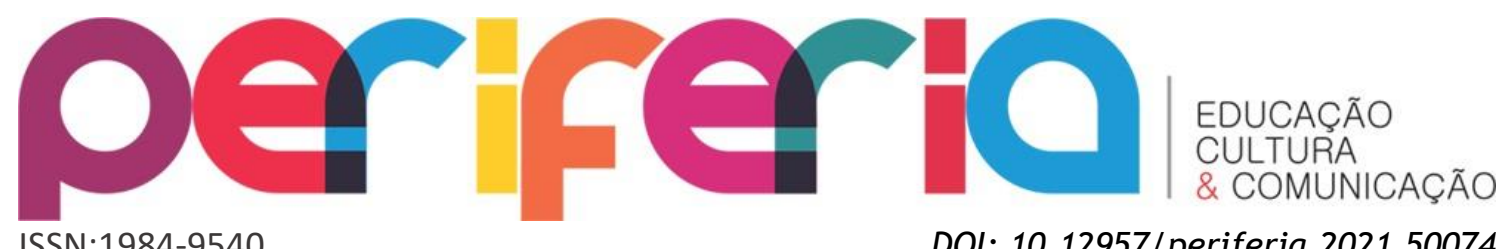

outros países da América do Sul, e do papel do Estado como indutor do crescimento econômico e da distribuição de renda.

Enquanto políticas estruturantes do campo da popularização da ciência, o Ministério da Ciência, Tecnologia e Inovação (MCTI) implantou a Secretaria de Ciência e Tecnologia para Inclusão Social (SECIS), que continha o Departamento de Difusão e Popularização da Ciência e Tecnologia, dedicado exclusivamente para divulgação científica. A SECIS se torna responsável pela elaboração de programas, supervisão e coordenação de ações do MCTI. Também foi criado o Comitê Temático de Divulgação Científica do Conselho Nacional de Desenvolvimento Científico e Tecnológico (CNPq), em 2004, que se mostrou um lugar de articulação entre os “divulgadores científicos” e o governo (FERREIRA, 2014).

Ainda nessa gestão, programas plurianuais foram traçados como formas de garantir apoio a projetos e eventos de divulgação e educação científica e à criação e desenvolvimentos de centros e museus de ciências, assim como fortalecimento da Olimpíada Brasileira de Matemática das Escolas Públicas e de conteúdos digitais para a educação científica. Políticas nacionais que atuavam diretamente junto à sociedade foram criados, como a Semana Nacional de Ciência e Tecnologia, em 2004; Programa de Apoio a Centros e Museus de Ciência; Programa de Apoio a Projetos Ciência Móvel; e Programa Nacional de Apoio às Feiras de Ciências da Educação Básica. (FERREIRA, 2014).

Ferreira (2014) identifica, entre os anos de 2003 e 2012, 41 editais para projetos de popularização da ciência, totalizando um orçamento de R\$ 92 milhões. Moreira (2006) destaca, inclusive, que tais políticas visavam a promoção de ações regionais de divulgação em parceria com governos estaduais e municipais, universidades e instituições de pesquisa e terceiro setor. Dentre as ações estaduais (no caso do Rio de Janeiro), se destacam, por exemplo, a criação, desde 2007, de programas como “Apoio à Difusão e Popularização da Ciência e Tecnologia no Estado do Rio de Janeiro" e “Apoio à Melhoria do Ensino em Escolas da Rede Pública Sediadas no Estado do Rio de Janeiro", que visavam a divulgação científica em todo o estado, bem como dar suporte financeiro a 


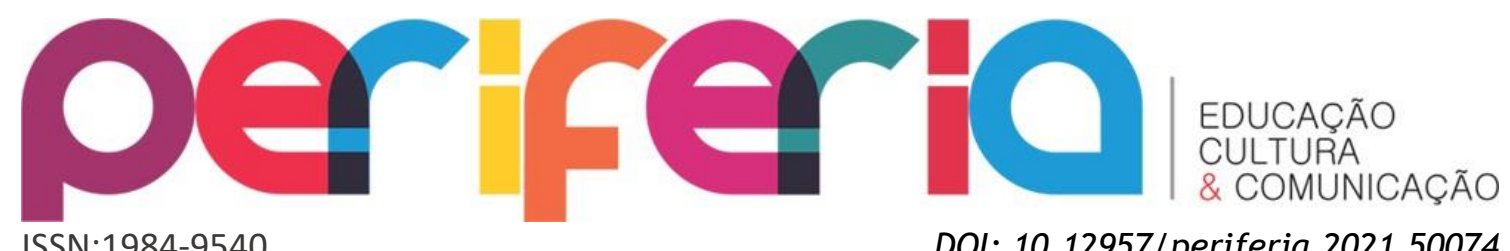

estratégias que, elaboradas por pesquisadores da academia, propusessem melhorias no espaço escolar e o processo de ensino-aprendizagem.

Percebemos, então, o aumento do apoio à popularização científica no país nas últimas décadas, principalmente com o estabelecimento de políticas públicas a partir de 2003. Entretanto, na contramão (e/ou em paralelo) a tais ações, ocorreu a ascensão de movimentos anticientificistas no Brasil influenciados por movimentos oriundos dos países do hemisfério Norte. Apesar de não serem recentes, os últimos anos têm sido marcados por questionamentos e rejeições acerca das descobertas científicas modernas, que pareciam hegemônicas na nossa sociedade. Essa ascensão de um pensamento anticientificista é bem exemplificada pelos movimentos terraplanista e antivacina, que vêm ganhando força, trazendo, inclusive, preocupações a nível de saúde mundial (Organização Mundial de Saúde [OMS], 2019).

A percepção do crescimento de movimentos anticientificistas promove uma inquietação acerca de fatores que podem explicar ou contribuir para tal fenômeno. Diante disso, partimos da hipótese que há uma disputa por espaços de significação e que, talvez, tais movimentos sejam reativos em relação a ampliação do acesso à ciência na população.

\section{Percurso metodológico}

O percurso metodológico desta pesquisa emerge, no primeiro momento, de uma revisão da literatura sobre políticas públicas de popularização da ciência, como já exposto. Entendendo o funcionamento de tais políticas e seu crescimento nos últimos anos, foi iniciada uma busca por argumentos que expliquem a posição dos movimentos elencados que pareceram ser os mais proeminentes, a saber, o terraplanismo e o movimento antivacina. Após isso, procurou-se articular nossos dados à uma análise discursiva com os estudos curriculares.

O segundo momento foi caracterizado por uma busca e jornais e revistas online de grande circulação acerca de matérias que tratassem sobre os movimentos anticientíficos no Brasil e no mundo. O objetivo foi procurar 


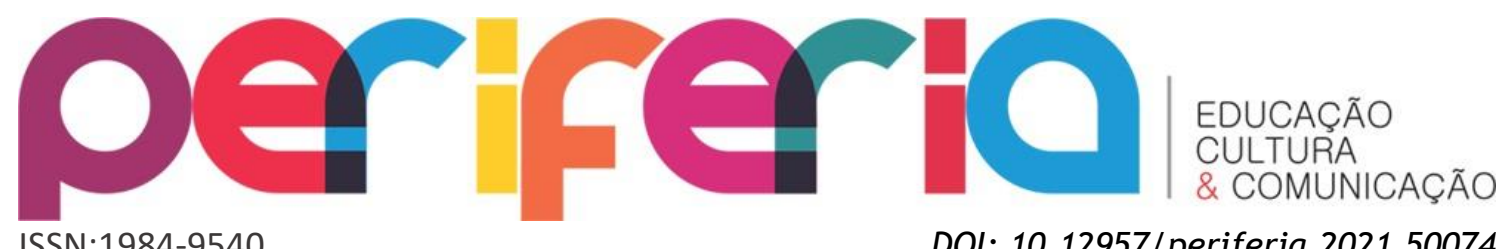

ISSN:1984-9540

DOI: 10.12957/periferia.2021.50074 entender como se dá a articulação desses movimentos, quais grupos da sociedade se fazem apoiadores, seus argumentos, a quantidade e se vem crescendo ou não o número de adeptos, os motivos pelos quais se tornaram membros, eventos e reuniões (se existirem), entre outras questões. Foi realizada visita às páginas (do Facebook e afins) desses movimentos. Além disso, também foram usadas pesquisas do Ministério da Saúde que mostram taxas de vacinação populacional anuais.

Com isso, partiu-se para o terceiro momento, a análise do material empírico, ancorados em uma abordagem discursiva que, antes de tentar validar verdades, interessa-se em compreender os movimentos de significação.

\section{Movimentos anticientificistas}

Os terraplanistas questionam o formato geóide da Terra, o heliocentrismo, bem como a gravidade. Creem que na escola nos passam um conhecimento manipulado. Para este movimento a verdade é que a cobertura do planeta é feita por um domo, onde o Sol e a Lua, considerados corpos menores, fazem seu percurso, enquanto o Polo Norte está no centro da Terra, com os continentes ao seu redor, e a Antártida circunda as bordas. Questionam ainda a credibilidade da National Aeronautics and Space Administration (NASA), que é apontada como uma "agência de efeitos especiais", que falsifica suas explorações espaciais desde a Guerra Fria. Há, segundo o grupo, uma teoria da conspiração que a NASA nunca enviou um homem à Lua, que foi, na verdade, uma estratégia elaborada devido à corrida espacial com a União Soviética ${ }^{4}$.

Apesar de diversas viagens, pesquisas e fotos, com a ajuda do desenvolvimento tecnológico e da astronomia, nota-se que cada vez mais pessoas do mundo inteiro se associam aos movimentos que defendem a forma da Terra plana e ignoram cientistas renomados, como Einstein e Newton, confiando nessa proposta. É necessário pontuar que diversas são as demandas

\footnotetext{
4 Optamos por não mencionar os sites e vídeos utilizados para que os algoritmos não potencializem discursos anticientificistas através da veiculação deste texto na Internet. As informações são facilmente localizadas online e as Figuras 1 e 3 exemplificam essas páginas.
} 


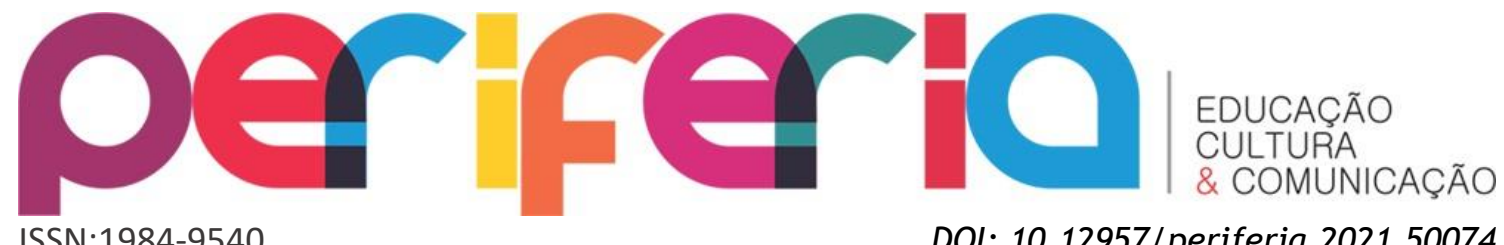

ISSN:1984-9540

DOI: $10.12957 /$ periferia.2021.50074 e características dessa organização - religião, poder político, tipo de família, tipo sociedade etc. A Revista Superinteressante, em matéria publicada em 2017, nos dá um breve histórico do começo deste movimento anti-globo (ELER; VERSIGNASSI, 2017). Nela, temos que em 1881, Samuel Rowbotham fez a publicação de um livro, baseado na bíblia e em estudos que fez por décadas, para desvendar "mentiras" que a ciência contava, o Astronomia Zetética - A Terra não é um globo. Robowtham criou discípulos, como o inglês Samuel Shenton, que em 1956, fundou a Flat Earth Society (Sociedade da Terra Plana) (Fig. 1), que em 2017, organizou a Flat Earth International Conference (1 ${ }^{\text {a }}$ Conferência Internacional da Terra Plana), na Carolina do Norte. O evento serviu também para divulgação do cruzeiro, que ocorreria em 2020, até a suposta borda do planeta.

Figura 1: A imagem mostra o print do site oficial do movimento Terraplanista.
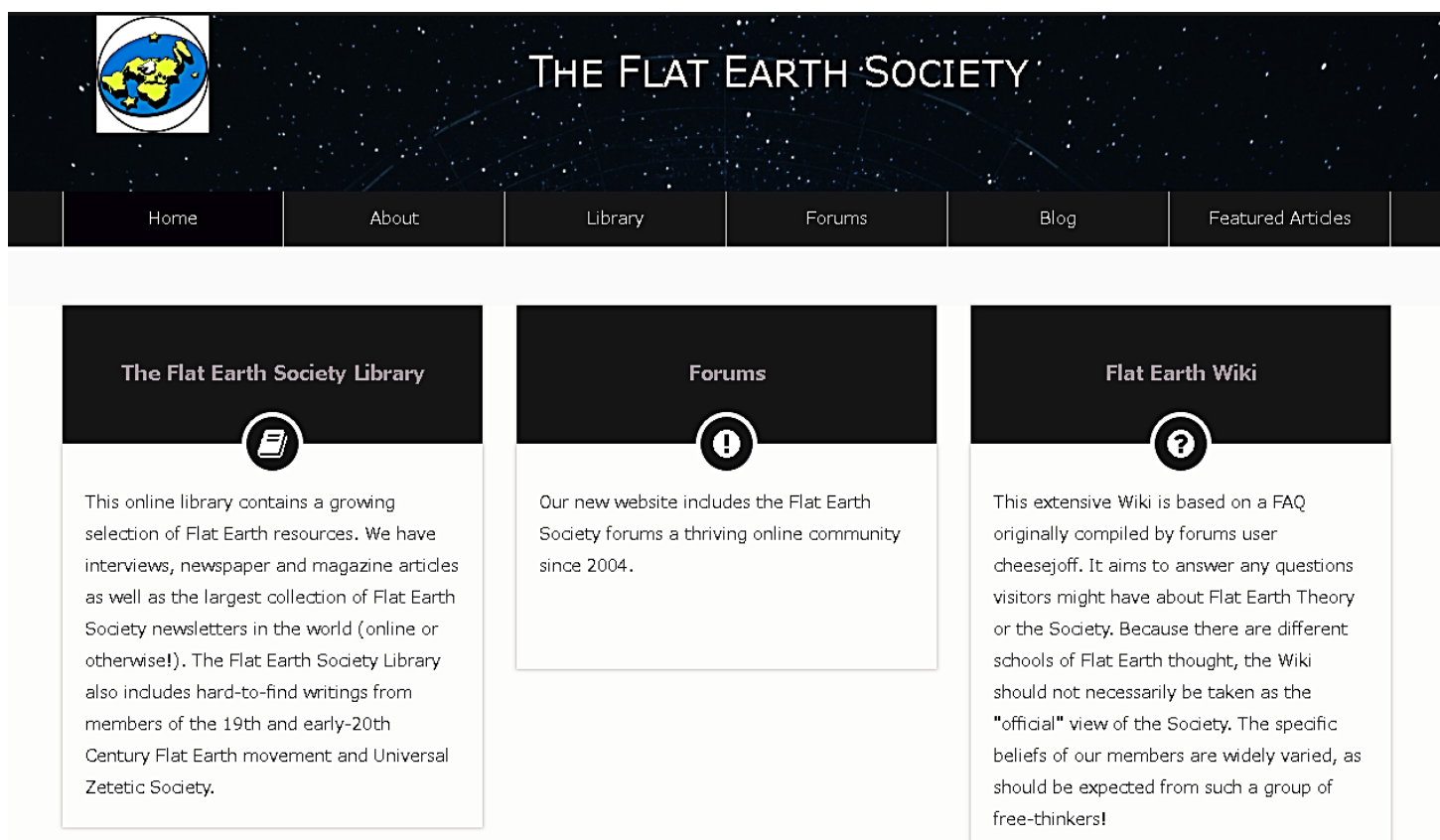

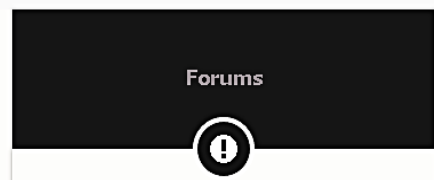

Our new website includes the Flat Earth Society forums a thriving online community since 2004 .

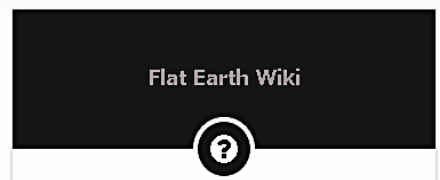

This extensive Wiki is based on a FAQ originally compiled by forums user cheesejoff. It aims to answer any questions visitors might have about Flat Earth Theory or the Society. Because there are different schools of Flat Earth thought, the Wiki should not necessarily be taken as the "official" view of the Society. The specific beliefs of our members are widely varied, as should be expected from such a group of free-thinkers!

Capturada em 12/09/2019.

Na reportagem feita pelo jornal El País, em março de 2019, é visto que o movimento tem maior expressividade nos Estados Unidos, onde apenas 66\% 


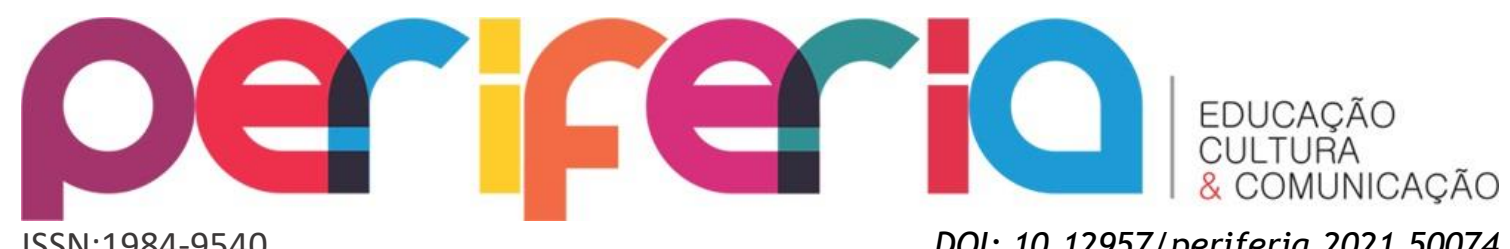

dos jovens (18-24 anos) tem certeza da forma do planeta. Seus ideais são difundidos, em especial, pelo YouTube, de acordo com um estudo realizado pela Universidade de Tecnologia do Texas. Os algoritmos dessas redes te levam cada vez mais para conteúdos referentes ao que já se buscou anteriormente, entrando num mar de (des)informação.

Outro movimento forte e perigoso é o antivacina, caracterizado pela hesitação de parte da população em se vacinar. No Brasil, a taxa de vacinação da população tem diminuído; em 2016, por exemplo, foi vista a menor taxa desde 2004, correspondente a 84\%, para uma meta de imunização de $95 \%$ da população, recomendada pela OMS. Cria-se um alerta no país para a volta de doenças antes consideradas erradicadas, como aconteceu entre 2013 e 2015, quando nos estados do Ceará e Pernambuco, tiveram surtos de sarampo, caxumba e rubéola, após queda nas taxas de vacinação, que atingiu 38 municípios (BBC, 2017).

Sobre a pandemia de COVID-19, os discursos antivacina dificultam a aderência da população às já escassas vacinas disponibilizadas no Brasil, potencializados através das políticas públicas e dos discursos de agentes públicos do executivo contrários à vacinação, através de redes de grande influência e enunciações ameaçadoras (VASCONCELLOS-SILVA; CASTIEL, 2015; ROCHEL DE CAMARGO JR, 2020). Apesar de todos os esforços mundiais para a disponibilização de vacina e imunização massiva, o Brasil, para citar um exemplo atual, segue sendo um dos principais focos da COVID-19, o que prejudica a ação sistêmica da vacinação como política de saúde coletiva; a vacinação é a principal forma de evitar a continuidade de proliferação da doença, que traz o risco do novas cepas não cobertas pelas vacinas atuais. Nesse sentido, o movimento antivacina se mostra como um dos principais problemas no enfrentamento da pandemia da COVID-19.

Alguns motivos são apontados para tal redução dos números, pesquisadores têm acreditado que a população ficou mais hesitante, principalmente, pelo aumento de "fake news", que tem dado força ao movimento. A imunização contra o sarampo possui quase duas décadas e salvou 21 milhões de pessoas e paralelamente diminuiu em $80 \%$ a mortalidade em 


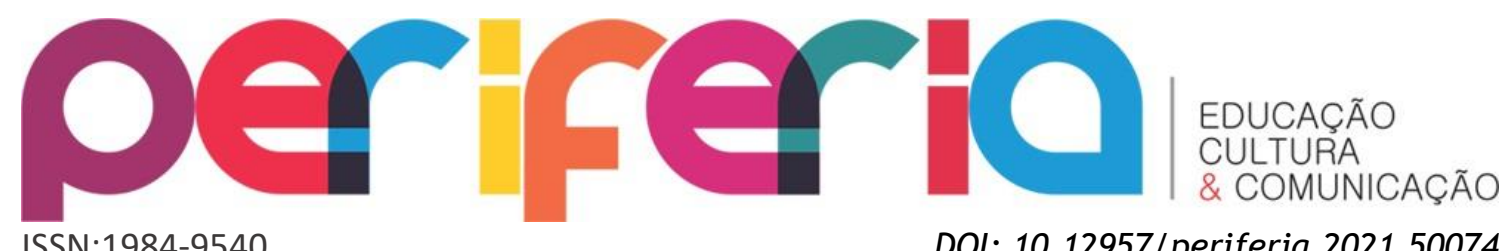

decorrência da doença. Contudo, reflexos a nível mundial já são observados com a redução nas vacinações, como, por exemplo, na Europa, que registrou um aumento de 400\% nos casos de sarampo em 2017 (BBC, 2017).

Em seu último relatório, a OMS elencou as dez ameaças à saúde que pretende começar a combater em 2019 com um plano estratégico com duração de cinco anos. Nele o movimento antivacina foi identificado como sendo um dos desafios de saúde para o ano vigente. A justificativa para fazer parte do movimento antivacina difere para cada indivíduo. Algumas pessoas veem problema na segurança que as vacinas oferecem e acreditam em cientistas malintencionados buscando se promover por meio delas. Outras, enxergam como suspeito o curto período entre as vacinações oferecidas, principalmente, às crianças. Há ainda quem leve em consideração a religiosidade ou certo "conspiracionismo", que sugeriria que a vacinação é disponibilizada pelos governos para controle populacional (MARTINS, 2019).

Apesar de parecerem estapafúrdias tais concepções, não podemos apenas ignorar tais concepções, mesmo porque elas não deixariam de existir e continuariam a conquistar adeptos. Nossa intenção é criar um espaço para debate sobre a origem e consequências desses movimentos para podermos compreendê-los. Para isso, nos ancoramos nas ideias do pós-modernismo e no pós-fundacionalismo, como a rejeição a verdades últimas e na indicação de possibilidades discursivas construídas a partir de narrativas contingenciais.

\section{Por uma abordagem discursiva}

Lopes (2013) realiza reflexões sobre tais movimentos, atentando que as características gerais do pós-modernismo são "a incredulidade perante as metanarrativas de legitimação da ciência e da ação humana, com as suas pretensões atemporais, a-históricas, totalizantes e universalizantes: dialética do espírito (Hegel), emancipação do sujeito racional ou do trabalhador”. Razão, verdade, totalidade, sujeito, progresso, espaço e tempo linear são colocados em crise. 


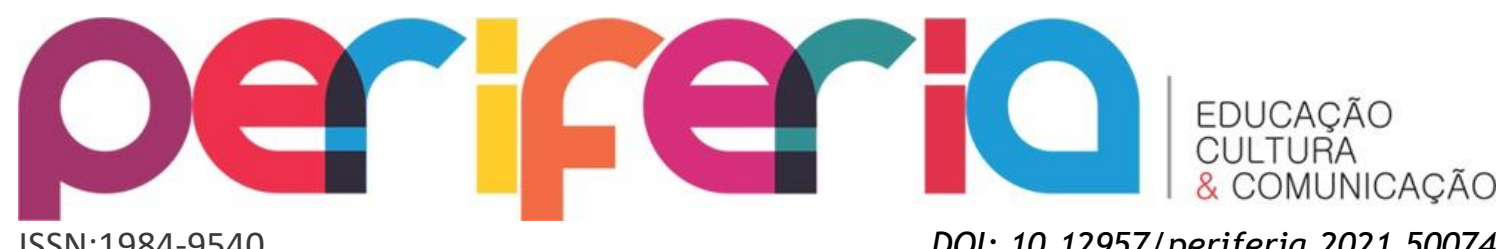

ISSN:1984-9540

DOI: 10.12957/periferia.2021.50074

No pós-modernismo a possibilidade de consenso depende de disputas e interesses, não existe autoridade final, uma narrativa totalizante que seja capaz de abranger e explicar o mundo. Não há um lugar onde se possa falar e nomear o mundo "fora da história, da linguagem, das construções discursivas, das identidades e experiências" (LOPES, 2013, p. 16). Os princípios que antes agiam como critérios de valor universais transcendentais parecem não operar mais da mesma forma, ampliando-se a percepção de relatividade, que, em contrapartida, implica certo movimento de reafirmação de verdades absolutas por certos grupos. Culturas, tempos e espaços são desafiados, sendo "as hierarquias do mundo pensadas como produzidas por discursos que conformam os nossos modos de interpretar”. Estamos lidando, então, com uma nuvem de elementos narrativos heterogêneos. Logo, o pós-modernismo privilegia essa heterogeneidade e a diferença como forças que nos desamarram do discurso cultural.

Já o pós-fundacionalismo, segundo Mendonça (2014), consiste numa constante interrogação crítica em direção aos projetos teóricos que visam se estruturar a partir de um fundamento último, como se tal fundamento fosse subjacente às próprias práticas políticas stricto sensu, como, por exemplo, o essencialismo econômico em última instância presente na tradição marxista (LACLAU; MOUFFE, 1985). Para Lopes, “o pós-fundacionalismo concorda com a impossibilidade de termos fundamentos fixos, questiona o objetivismo, valoriza a heterogeneidade, o indeterminismo e o anti-essencialismo tal como o pósestruturalismo" (2013, p.16).

Neste sentido, tanto pós-modernismo quanto pós-fundacionalismo interrogam a ideia de verdades últimas, indicando possibilidades discursivas construídas a partir de narrativas contingenciais. Há, então, pelo pósmodernismo, a ideia de que não é possível haver um consenso último sobre este ou aquele sentido, uma vez que este vai se constituindo socialmente de forma agonística; e pelo pós-fundacionalismo, reforça-se a ideia de fluidez dos sentidos produzidos, ao mesmo tempo em que se entende que é a compreensão de fixação de tais sentidos que permite a operacionalização deles em dimensão social. 


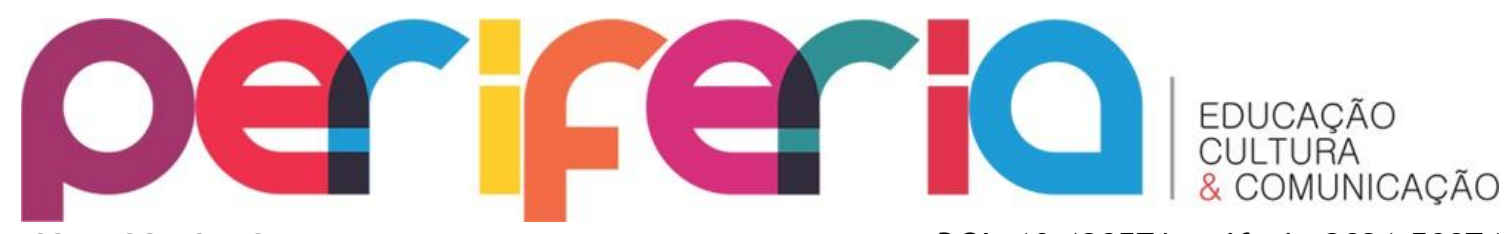

ISSN:1984-9540

DOI: $10.12957 /$ periferia.2021.50074

Buscamos, portanto, aproveitarmos estes movimentos de análise discursiva para tentar compreender as lógicas que viabilizam os movimentos anticientificistas para além do que é ou não “verdade”, mas tentando seguir as migalhas de pão que, espalhadas a esmo, podem indicar elementos que contribuam para compreensão deste fenômeno. As ideias que orbitam teorias pós-modernas e pós-fundacionais fornecem uma arena na qual a noção de “verdade" é menos importante que as produções discursivas em si, já que são estas que, segundo suas próprias narrativas, produzirão o que chamarão de “verdade”. Não nos importa tanto aqui que Aristóteles tenha provado através de empiria a esfericidade da Terra na Antigudade em 330 a.C., mas que tipos de argumentos e dispositivos discursivos os adeptos do chamado “terraplanismo" utilizam buscando legitimação.

Lopes, em 2013 afirmou que o pós-fundacionalismo "não rejeita os fundamentos nem aposta na dispersão das diferenças e dos contextos isolados” (p. 16), preconizando o trabalho com fundamentos contingentes, mas também precisa de algum nível de fixação provisória de fundamentos instáveis. A contingência é obrigatoriamente necessária, haja vista que uma identidade ou evento só é possível se não for pleno (MARCHART, 2007). Logo, na esteira de Laclau (2008), a autora entende que uma identidade depende das condições que não são resultados desse mesmo ser, ou seja, a plenitude de uma identidade é inalcançável. Uma identidade, que pode ser a sociedade, Estado, sujeito ou qualquer outra entidade, não precisam ter a sua plenitude prevista para existir, diferententemente do que se pensava anteriormente; logo, a lógica da identidade não deixa de existir, mas, enquanto antes se encarava como se fossem fixas e plenas, no pós-fundacionalismo elas passam a ser analisadas enquanto discursos pretensamente fixos, mas efetivamente fluídos e contingentes. Alba e Lopes (2014, p.50), citando Mouffe (2011), indicam que tudo pode ser explicado de outra maneira, e o que aceitamos como natural, “nada mais é do que uma sedimentação de práticas hegemônicas marcadas pela exclusão, instituídas por atos de poder, de outras possíveis ordens”.

Nessa perspectiva, buscamos desmontar a ideia de modelo de que terra plana e movimento antivacina são inverdades, não-verdades, pós-verdades ou 


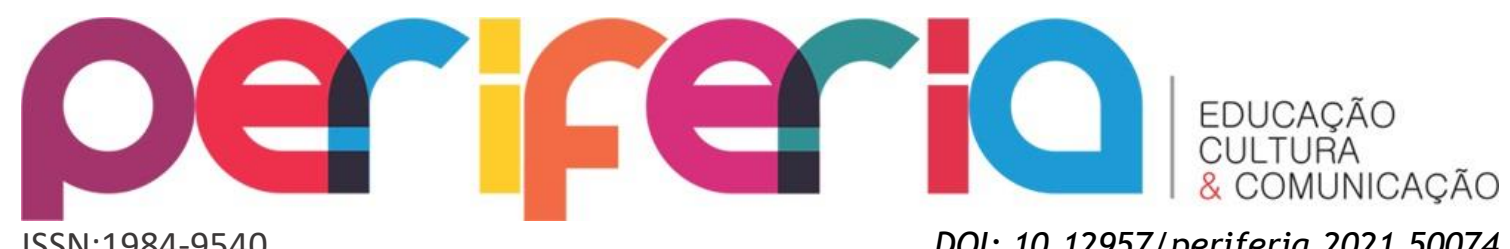

ISSN:1984-9540

DOI: 10.12957/periferia.2021.50074 falsos (livre denominação). Um cientista absolutista e positivista diria, por exemplo, que o modelo de Terra plana é falso, enquanto que o modelo de Terra redonda é verdadeiro (LIMA et al., 2019). Pretendemos aqui refletir sobre tais pontos de vista antagônicos. Entendemos que os modelos são duas propostas que se articulam em rede com outras propostas. Enquanto o modelo da Terra plana se entrelaça com concepções bíblicas e pré-newtonianas, o modelo da Terra redonda se articula com propostas de dados empíricos e experimentos ligados a concepções newtonianas. E que estas duas propostas estão em embate. Entretanto, salientamos que a amplitude de alcance das duas propostas não é a mesma. O número de proposições que conseguem ser mobilizadas pelo segundo modelo é muito maior que o do primeiro. Enquanto a afirmação de que a Terra é plana pode se sustentar por alguns metros, a afirmação de que a Terra é redonda pode ser articulada em um espaço bem maior. Mesmo assim, a afirmação de que a Terra é redonda não consegue se sustentar também por muito tempo, pois não se entrelaça com os dados de relevo e achatamento da Terra (LIMA et al, 2019).

Desta forma, nosso objetivo aqui não é defender um ponto de vista suplantando o outro, mas compreender de que maneira eles se articulam e se constroem mutuamente, em um processo de alteridade. 0 movimento anticientificista emerge na medida em que a ciência começa a questionar verdades até então hegemonizadas, baseadas em discursos religiosos e de senso comum, por exemplo. Na medida em que a ciência ganha espaço na sociedade, outros discursos são enfraquecidos e, então, reagem produzindo narrativas que, por sua vez, tentam pôr em xeque a verdade que a ciência moderna aponta. É, então, a ascensão da ciência na sociedade que, por reação, produz movimentos anticientificistas.

Quando a Igreja Católica, na Idade Média, perseguia pessoas que possuíam saberes e comportamentos diferentes, ela estava tentando assegurar seu próprio lugar de detentora da verdade. Neste sentido, a ciência passa a ser atacada quando produz discursos que enfraquecem outras enunciações até então sedimentadas; Copérnico e Galileu, por exemplo, apesar de tratarem de um modelo heliocêntrico (que ia contra os dogmas da Igreja Católica), 


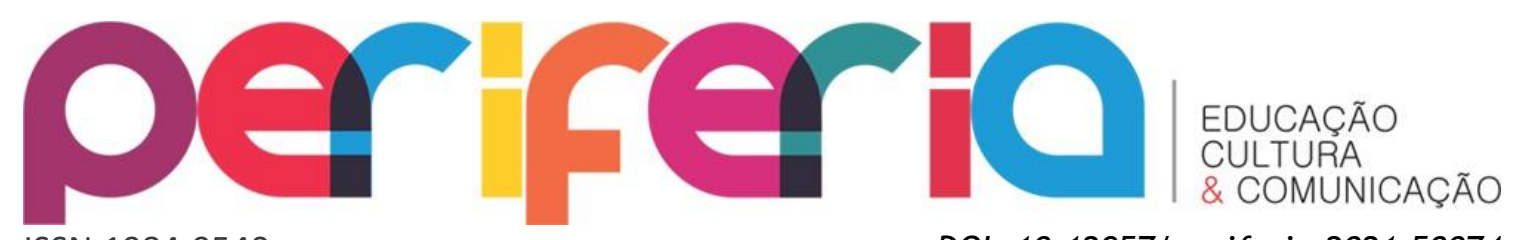

ISSN:1984-9540

DOI: $10.12957 /$ periferia.2021.50074 receberam tratamentos distintos. 0 primeiro foi, em certa medida, aceito mesmo entre religiosos, enquanto o segundo, cujas publicações emergiram em meio a um período de enfraquecimento da Igreja Católica devido à Reforma Protestante, teve um tratamento mais severo, já que, por conta do contexto, seu discurso foi considerado mais perigoso.

O mesmo acontece com o movimento antivacina, que está ligado a um artigo do pesquisador Andrew Wakefield, na revista científica The Lancet, de 1998, que relacionava a ampla vacinação da sociedade com o aumento no número de casos de crianças autistas. Após essa publicação, o cientista foi mundialmente questionado e diversas outras pesquisas foram realizadas em um esforço conjunto para que tal proposição fosse derrubada. Após alguns anos o investigado foi obrigado a se retratar publicamente, afirmando que seu trabalho continha diversos erros metodológicos. Porém, apesar de desmentido por estudos de diferentes grupos de pesquisa, ainda hoje essa publicação é usada como referência para embasar tal movimento e captar novos membros.

Muitas destas discussões e entraves acontecem dentro do ambiente escolar e estão diretamente atreladas ao currículo. Para Lopes e Macedo (2011), o currículo é uma arena de disputa por produção de sentidos, sendo um espaço privilegiado por/para legitimação social e hegemonização de discursos. É neste terreno curricular que diferentes formas de saberes e conhecimento se articulam, promovendo tensões e hibridizações para/nos processos de subjetivação. Pereira (2014, p. 27) propõe uma ilustração (Fig. 2) para compreender a lógica de produção de currículos a partir da relação com os conteúdos. 


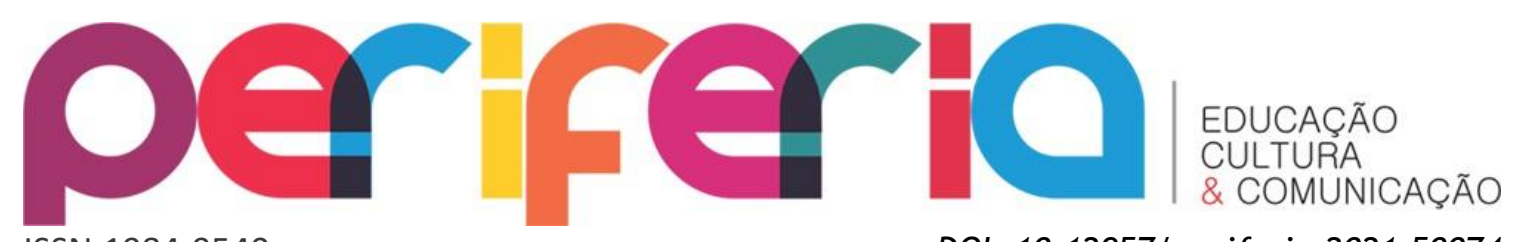

Figura 2: Esquema ilustrativo sobre a relação entre saber, conhecimento e currículo.

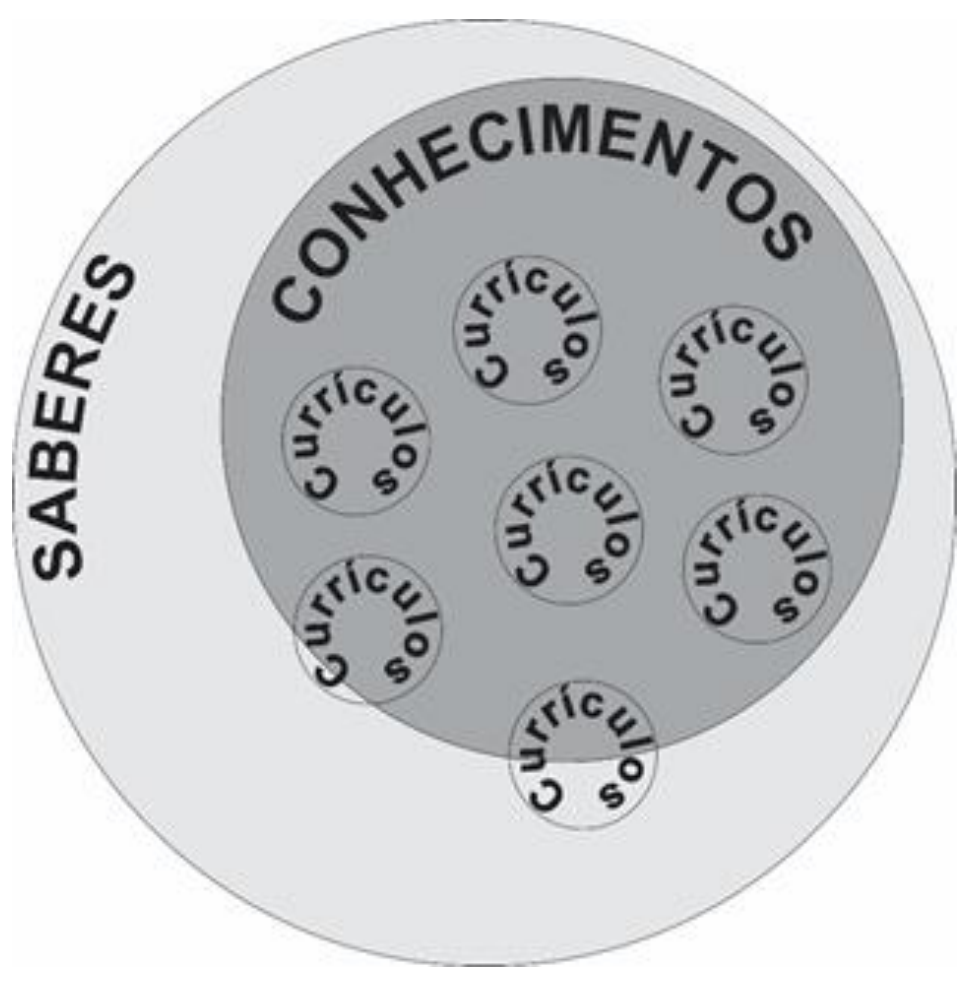

Fonte: Pereira, 2014.

O círculo maior (SABERES) refere-se a todo o tipo de produção do pensamento humano. O círculo interno mais escuro compreende aos conhecimentos socialmente validados, em geral, através de um discurso científico positivista, e que, como é possível observar, servem como base para a organização, em maior ou menor grau, dos currículos educacionais. É preciso observar, contudo, que há mais elementos envolvidos nos processos educacionais que apenas os conteúdos, que, inclusive, também não são neutros ou acríticos, mas emergem de arenas de disputa por significação (LOPES; MACEDO, 2011).

Como dito, os currículos escolares são espaços de disputa, muitos tipos de conhecimento são excludentes entre si e o processo de democratização do conhecimento científico tensiona ainda mais os embates deste com outras formas de conhecimento socialmente estabelecidas, como o conhecimento popular e o conhecimento religioso. A máxima conhecimento é poder se aplica 


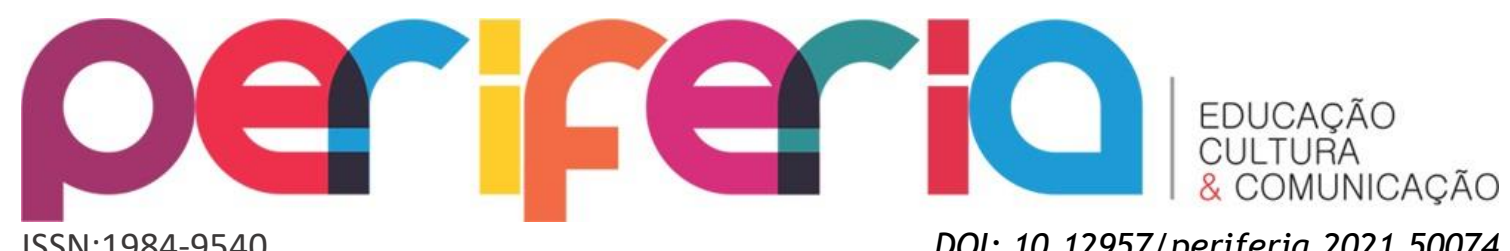

perfeitamente a esta questão: validar e legitimar determinado conhecimento como verdade única significa, necessariamente, a inferiorização dos outros à condição de folclore ou mentiras, o que, certamente, não é de interesse de grupos nos quais estes conhecimentos deslegitimados se dão.

A globalização acarreta relações e jogos de negociação ou tensão entre currículos escolares e práticas sociais, entre dimensões do global e local em suas interferências "na transformação das identidades" dos sujeitos, na sociedade (HALL, 1997). A vivência no ambiente transversal globalizado permite a convivência entre diversos tipos de identidade, enquanto culturas hibridizadas, o que favorece a riqueza multi/pluri/inter/transcultural que marca os contextos culturais do cotidiano e da escola (HALL, 1997; CANCLINI, 1998) na relação, também, com as ciências. A escola que hoje temos tem por tradição, ao longo da história, o intuito de "moldar" o sujeito segundo um "ideal" cerceado por interesses de uma elite, que orientava regras e práticas pedagógicas, com controle do acesso à escolarização, ao tipo de escola, ao currículo e ao ensino, considerando-se diferentes classes sociais.

Appadurai (2004), relata que temos passado pelo fenômeno da globalização há vários séculos. Entretanto, no cenário atual, com o aumento de informação e comunicação gerados pela aceleração do desenvolvimento tecnológico, há um fluxo maior de alcance e interação. Portanto, "se a "globalização" é um fenômeno antigo, a atual rápida e crescente "globalização" cultural é motivada pelo atual desenvolvimento dos meios de comunicação social e as migrações humanas que marcam o mundo" (TIVIANE, 2015, p. 37). E, devido a circulação simultânea de ambas, os meios de comunicação de massas, possibilitam a crítica e o prazer do coletivo, consequentemente, grupos com pessoas que tem sentimentos em comum são criados. Ademais, o autor relaciona que grupos distantes, mesmo que não se conheçam, se relacionam para compartilhar das mesmas coisas e pensamentos, graças ao boom tecnológico.

Nesse processo, as manifestações globais que ocorrem, vão além dos modelos centro-periferia, por exemplo, mas criam uma relação entre Estados e nações, originando uma economia cultural global que desalinha os planos 


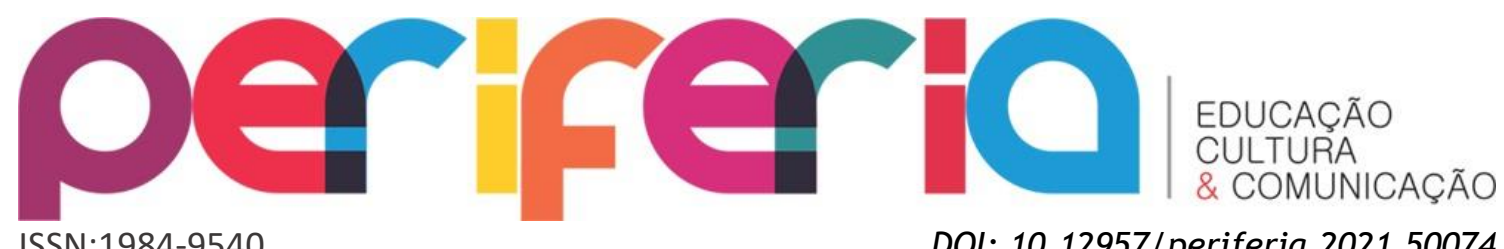

econômico, cultural e político. Baseando-se na figura de paisagem, Appadurai nomeia cinco dimensões dos fluxos culturais globais, etnopaisagens, mediapaisagens, tecnopaisagens, financiopaisagens e ideopaisagens.

Paisagem como sufixo permite-nos apontar a forma fluida, irregular destes horizontes, formas que caracterizam o capital internacional tão profundamente como a moda internacional do vestuário. Estes termos com sufixo comum paisagem indicam também que estas não são relações objetivamente dadas que parecem o mesmo de todos os ângulos de visão, são construções profundamente perspectivadas, inflectidas pela localização histórica, linguística e política de diferentes tipo de atores: Estados-nações, empresas multinacionais, comunidades da diáspora, bem como grupos e movimentos subnacionais (sejam eles religiosos, políticos ou econômicos); e mesmo de grupos íntimos e próximos, como aldeias, bairros e famílias. Estas paisagens são, portanto o material de construção dos mundos imaginados, isto é, os múltiplos universos que são constituídos por imaginações historicamente situadas de pessoas e grupos espalhados pelo globo. Em todo globo, hoje, muitas pessoas vivem nesses mundos capazes de contestar e por vezes até subverter os mundos imaginados na mente oficial e na mentalidade empresarial que as rodeia (APPADURAI, 2004, p. 50-51).

Neste trabalho, as mediapaisagens, são de nosso interesse particular. São entendidas como a capacidade de distribuição eletrônica para produzir e disseminar informação, como os jornais, as revistas, os canais de televisão e filmes, que são de interesse público e privado em todo o globo, por ter um enorme acervo de imagens e narrativas que possui um alcance mundial, além de misturar o mundo da mercadoria e das notícias e da política. A mídia ao sugerir a disponibilidade das coisas, dá espaço a imaginação coletiva que, conforme tem seu poder aumentado sobre a realidade nos fluxos globais, ganha mais importância. Tem-se então, uma ligação entre as imagens geradas e o imaginado, que constitui imaginações de pessoas em todo lugar do planeta. Os meios de comunicação de massa são ressignificados, sendo afastados da imagem de produtores de cultura alienante e passam a ser elementos (re)produtores de cultura e sentido.

Utilizando deste conceito, trabalhamos, então, com a disseminação dessas proposições "não-verídicas" ou que não se articulam com o 


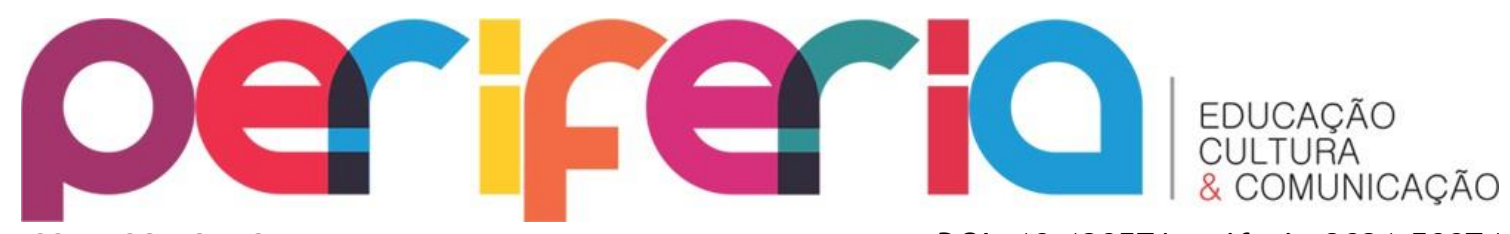

ISSN:1984-9540

DOI: 10.12957/periferia.2021.50074 conhecimento científico atual. Tais enunciados "Terra plana" e "antivacina" são amplamente divulgados nas mídias sociais, compartilhados por diversos seguidores, dentro e fora do país. Essa rede de compartilhamentos provoca uma reverberação de suas proposições mesmo que elas não sejam legitimadas nos meios de mídia de comunicação em massa tradicionais (televisão, rádios e jornais, por exemplo). Levando a uma maior captação de membros e de disseminação de suas ideias. Abaixo vemos um exemplo de uma página do Facebook (Fig. 3) chamada "A Terra é Plana - Flat Earth", que dissemina conteúdos sobre o tema. Percebemos na imagem que ela articulada com conteúdos de outras plataformas digitais, como o YouTube, e em outros idiomas.

Figura 3: Imagem da página do facebook “A Terra Plana”, capturada em 31/07/2019.

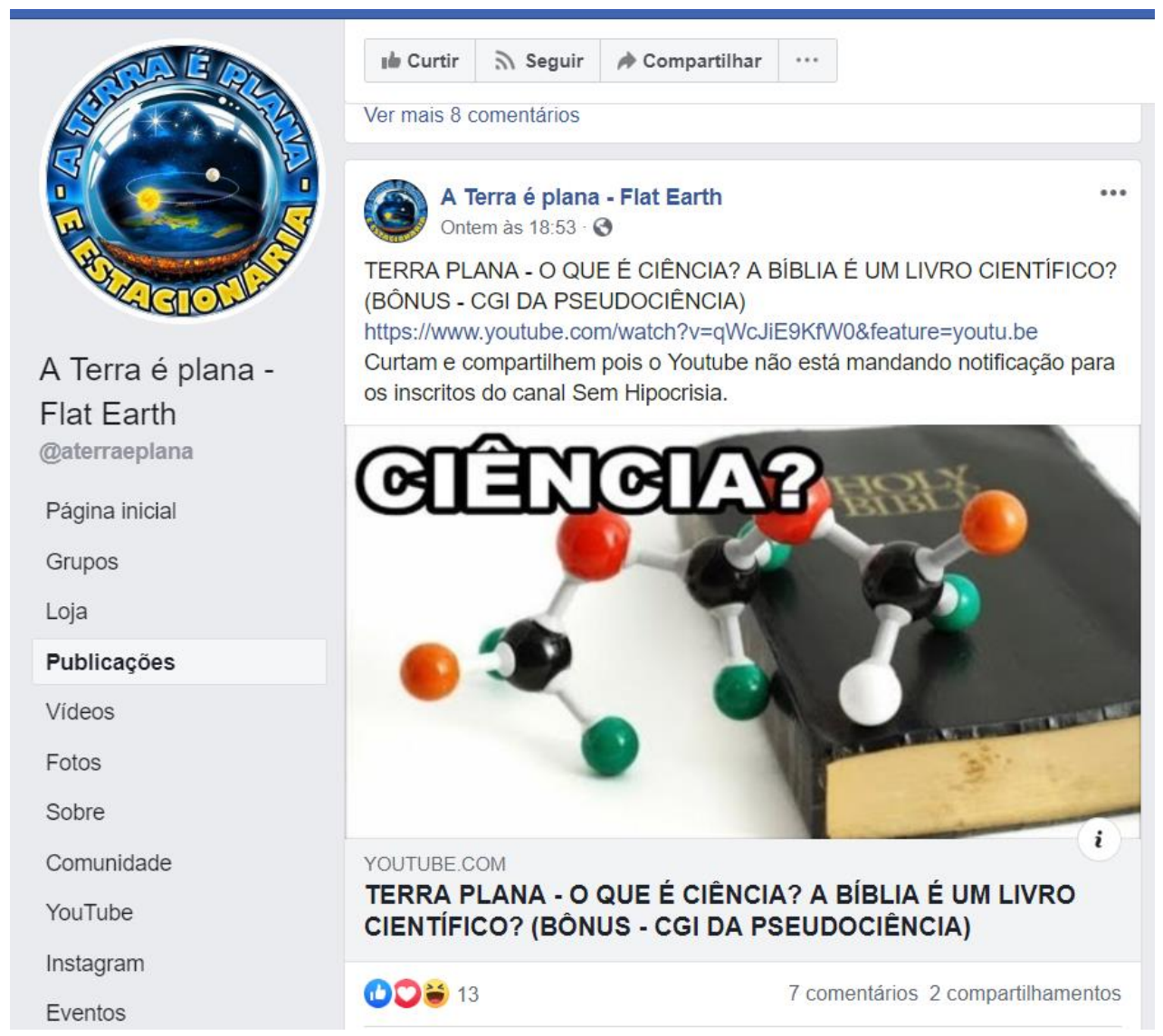

Por outro lado, para Marques (2001, p. 23), “se antes decorria muito tempo entre as descobertas científicas, a aplicação delas aos processos 


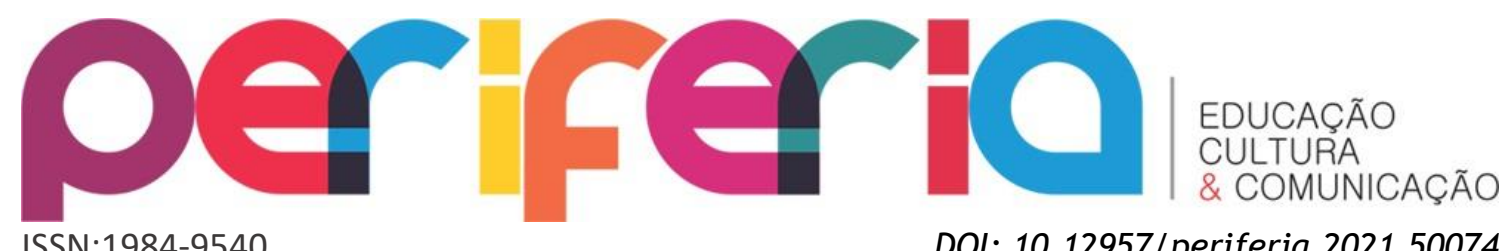

produtivos, aos setores de serviços e ao ensino nas salas de aula, presentemente esses tempos alongados e esses espaços separados se aproximam". Cada vez com mais rapidez as informações e resultados das pesquisas científicas chegam até as diversas esferas da sociedade. Um cientista, situado em seu lugar social, faz ciência para validar, no âmbito dela, os conhecimentos nela produzidos. Nem sempre se envolve na tarefa de publicizar conhecimentos científicos a outras esferas da sociedade, nem mesmo à escola, cabendo a outros profissionais a função de disponibilizar o acesso a tais conhecimentos.

Por outro lado, Lopes (2006, p. 36) afirma que "grupos de pesquisa que têm foco central na escola ou nos movimentos sociais tendem a incorporar as discussões teóricas mais contemporâneas sobre a cultura e a crítica aos marcos universalistas da modernidade". Com isso, auxiliam bastante no questionamento da pretensa homogeneidade e subordinação do cotidiano a um poder central.

Nesse sentido, cabe reafirmar o papel essencial do professor e dos materiais de divulgação e/ou popularização da ciência na recontextualização dos conhecimentos científicos para o âmbito especificamente escolar. Segundo Zamboni (2001, p. 50), quando ultrapassa o muro da comunidade científica, a “língua” dos cientistas torna-se, para a maioria da coletividade leiga, uma língua estrangeira, necessitando de um "tradutor" que a torne acessível à grande massa de homens comuns, dissociados na elite científica e, portanto, colocados à margem de um saber cada vez mais técnico, numa sociedade cada vez mais funcionalmente especializada.

Percebe-se, então, a relevância dos sentidos de verdade que as pessoas passam a construir ao longo de suas vidas. A escola, enquanto instituição social atrelada ao ensino e ao conhecimento, figura espaço privilegiado na hegemonização de tais sentidos. Segundo Gohn (2006) podemos encarar os processos educativos, sempre inerentes às atividades humanas, em três categorias: a educação formal; a educação não-formal; e a educação informal. Compreendemos que a popularização da ciência pode se dar, com diferentes manifestações e dimensões, em todos estes espaços educacionais. 


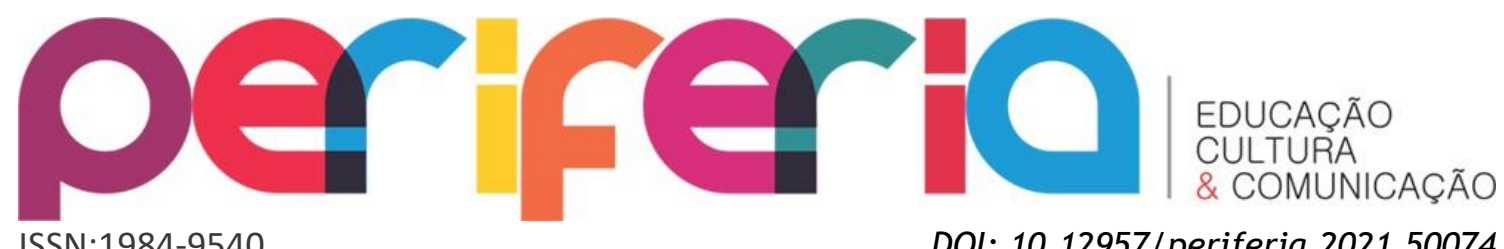

ISSN:1984-9540

DOI: 10.12957/periferia.2021.50074

Para a autora, na educação formal estes espaços são os do território das escolas, são instituições regulamentadas por lei, certificadoras, organizadas segundo diretrizes nacionais. Há a presença obrigatória do ensino de ciências, e a própria construção e manifestação dos demais campos disciplinares estão pautadas mais fortemente sob o conhecimento científico. Na educação nãoformal os espaços educativos localizam-se em territórios que acompanham as trajetórias de vida dos grupos e indivíduos, fora das escolas, em locais informais, locais onde há processos interativos intencionais (a questão da intencionalidade é um elemento importante de diferenciação). Manifesta-se na popularização da ciência através de estratégias de ensino não escolares, como museus, planetários e zoológicos, por exemplo.

Já a educação informal tem seus espaços educativos demarcados por referências de nacionalidade, localidade, idade, sexo, religião, etnia. São exemplos de espaços informais de educação a casa onde se mora, a rua, o bairro, o condomínio, o clube que se frequenta, a igreja ou o local de culto a que se vincula sua crença religiosa, o local onde se nasceu, entre outros. Onde pode ser oferecido acesso a informações científicas difusas no cotidiano.

Aproveitando as considerações de Gohn (2006), podemos pensar que a educação formal, ancorada fortemente em pressupostos modernos $\mathrm{e}$ científicos, oferece meios de popularização da ciência, que disputa possibilidades de enunciação com discursos oriundos de outros espaços, quer de educação não-formal ou informal. Em um movimento reativo, grupos que até então operavam em espaços não-formais e informais, passam a pleitear voz nas deliberações de dos ditos espaços formais.

Como exposto no início deste texto, nos últimos anos, diversas políticas públicas relacionadas ao aumento da popularização científica se articularam nesses espaços citados. Entretanto, mesmo assim, houve um amplo movimento de disseminação e captação de novos membros de comunidades anticientificistas. Nesse contexto, entendemos que a política não é feita apenas nas alcovas das grandes lideranças político-partidárias, e sim, de forma contínua e cíclica em todos os âmbitos da sociedade e para todos estes, e que essa construção se dá através de diálogos de diferentes discursos (LOPES, 2006) 


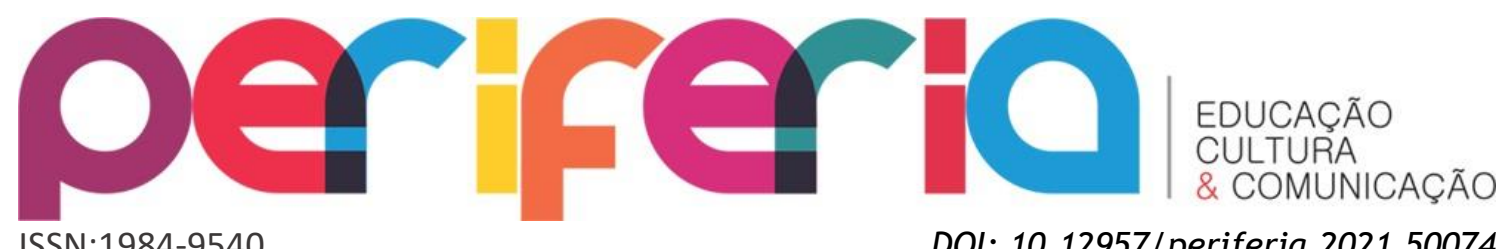

ISSN:1984-9540

DOI: 10.12957/periferia.2021.50074

Por conta disso, a dificuldade existente entre se forjar uma política e disseminá-la em diferentes ambientes e grupos. A ruptura dos pensamentos políticos, apesar de acontecer de tempos em tempos, precisa correr em paralelo à mudança de pensamento das próprias massas. Ball, (1994) salienta também que os autores das políticas não podem controlar todos os sentidos que serão lidos, ainda que estejam sempre buscando limitar essas possíveis leituras. As ações que visam restringir os sentidos possíveis de serem lidos incluem os dispositivos legais, os sistemas de avaliação e os sistemas de financiamento, como é o caso deste programa. Mas a cada uma dessas ações há necessidade de associar mecanismos simbólicos de legitimação de seus discursos (LOPES, 2004).

\section{À guisa de conclusão}

Concluímos, pois, que os movimentos anticientificistas emergem como resposta à ampliação da difusão dos conhecimentos científicos, de diferentes áreas da ciência, uma vez que a ciência, muitas vezes, apresenta dados que fazem desmoronar dogmas construídos socialmente, os quais, muitas vezes, são utilizados como formas de posicionamento social, seja em nível intelectual, religioso ou econômico. A escola, como espaço privilegiado de produção de sentidos, é disputada como ferramenta de hegemonização por ambos os campos, seja o do conhecimento científico, seja o dos conhecimentos populares e religiosos. Não é o caso de invalidar ou invisibilizar quaisquer um destes em absoluto, mas compreender as tensões e embates que se constituem a partir de diferentes arranjos sociais, e buscar estratégias de negociação que considerem as manifestações científicas e culturais como válidas e coexistentes, oferecendo perspectivas diferentes sobre os mesmos objetos e sendo capazes de hibridizar em novos olhares e práticas, tendo como norte o pleno desenvolvimento e dignidade das pessoas. Assim, o investimento na ciência e em sua popularização é uma necessidade urgente, tendo em vista que promove melhorias na qualidade de vida da população, bem como é necessário que este se desdobre em popularização científica, a fim de sedimentar tais conhecimentos como legítimos e frequentes no cotidiano. 


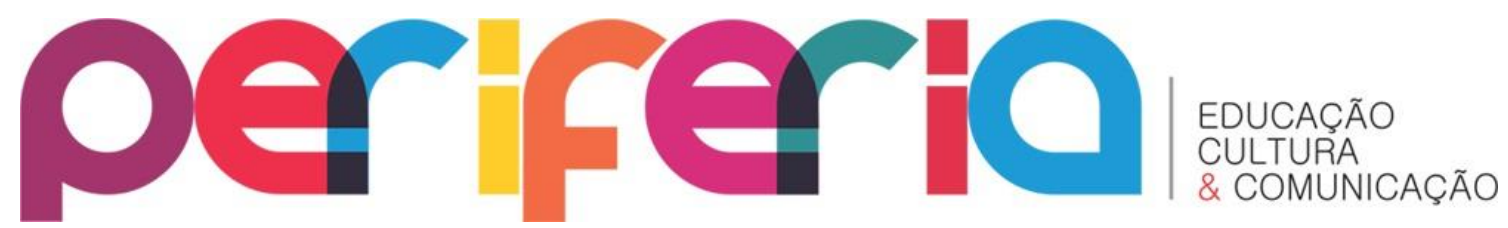

ISSN:1984-9540

DOI: $10.12957 /$ periferia.2021.50074

\section{Referências}

APPADURAI, Arjun. Dimensões culturais da globalização. Lisboa: Teorema, 2004, pp. 15-51.

BALL, Stephen John. Education reform - a critical and post-structural approach. Buckinghan: Open University, 1994.

BRITO, Fátima; FERREIRA, José Ribamar; MASSARANI, Luisa. (org.). Centros e Museus de Ciência do Brasil. Rio de Janeiro: ABCMC: UFRJ. FCC, Casa da Ciência: Fiocruz. Museu da Vida, 2009. 232 p.

CANCLINI, Nestór García. Culturas hibridas. São Paulo: EDUSP, 1998. Educação nas Ciências. Ijuí, RS: Ed. Unijuí, v.1, no1, p.21-43, jan/jun. 2001.

FERREIRA, J. R. Popularização da ciência e as políticas públicas no Brasil (2003- 2012). Tese - Instituto de Biofísica Carlos Chagas Filho, Programa de Pós-Graduação em Ciências Biológicas - Biofísica. UFRJ, 2014. 185 f., p. 5393.

ELER, Guilherme; VERSIGNASSI, Alexandre. A "ciência” da Terra plana. Revista Superinteressante, 23 out. 2017. Disponível em: <https://super.abril.com.br/ciencia/a-ciencia-da-terra-plana/>. Acesso em: 12 set. 2019.

FONSECA, Rodrigo Rodrigues. Política Científica e Tecnológica para o desenvolvimento social: uma análise do caso brasileiro. Tese (Doutorado em Geociências) -Instituto de Geociências, Universidade Estadual de Campinas, Campinas, 2009. 343 f., p. 10

GOHN, Maria da Glória. Educação não-formal, participação da sociedade civil e estruturas colegiadas nas escolas. Ensaio: Avaliação e Políticas Públicas em Educação, 2006, vol. 4, n. 50. p. 27-38.

GUIMARÃES, Keila. Vacinação em queda no Brasil preocupa autoridades por risco de surtos e epidemias de doenças fatais. BBC News, 2017. Disponível em: $<$ https://www.bbc.com/portuguese/brasil-41045273 >. Acesso em: $07 / 04 / 2020$.

HALL, Stuart. A centralidade da cultura. Educação \& Realidade, Porto Alegre, n. 22, v. 2, jul.-dez. 1997.

LACLAU, Ernesto; MOUFFE, Chantal. Hegemony and socialist strategy: towards a radical democratic politics. London: Verso, 1985.

LACLAU, Ernesto. Atisbando el futuro. In Simon Critchley \& Oliver Marchart (Orgs.), Laclau: Aproximaciones críticas a su obra (p. 347-404). México: Fondo de Cultura Económica, 2008. 


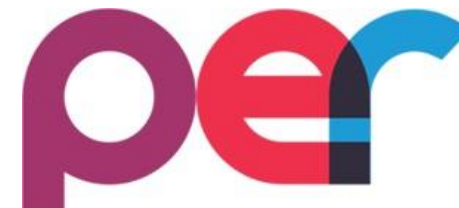

ISSN:1984-9540
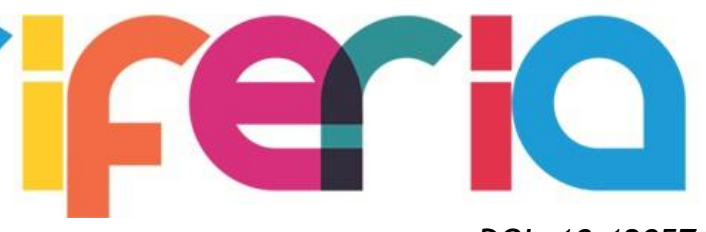

EDUCAÇÃO

CULTURA

\& COMUNICAÇÃO

DOI: $10.12957 /$ periferia.2021.50074

LIMA, Nathan Willig; VAZATA, Pedro Antonio Viana; MORAES, Andreia Guerra OSTERMANN, Fernanda; CAVALCANTI, Claudio José de Holanda. Educação em Ciências nos Tempos de Pós-Verdade: Reflexões Metafísicas a partir dos Estudos das Ciências de Bruno Latour. Revista Brasileira De Pesquisa Em Educação Em Ciências, 19, 2019. 155-189.

LOPES, Alice Casimiro; MACEDO, Elizabeth. Teorias de currículo. São Paulo: Cortez, 2011.

LOPES, Alice Casimiro. Políticas de currículo: mediação por grupos disciplinares de ensino de Ciências e matemática. In: LOPES, Alice Casimiro; MACEDO, Elizabeth. (Org.) Currículo de Ciências em debate. Campinas, Papirus, 2004.

LOPES, Alice Casimiro. Discursos nas políticas de currículo. Currículo Sem Fronteiras, São Paulo, v. 6, n. 2, p.33-52, Jul/Dez. 2006.

LOPES, Alice Casimiro. Teorias pós-críticas, política e currículo. Educação, Sociedade \& Culturas, v. 39, p. 7-23, 2013.

MARCHART, Oliver. Post-Foundational Political Thought: political difference in Nancy, Lefort, Badiou and Laclau. Edinburgh: Edinburgh University Press, 2007.

MARTINS, Elisa. A nova revolta da vacina. Época. 20 set.2019. Disponível em <https://epoca.globo.com/brasil/anova-revolta-da-vacina-23960872> Acesso em: 24 set. 2019.

MARQUES, Marcos Osorio. Educação nas Ciências: os novos desafios. Revista Maruyama, S. Aquecimento global?. Oficina de Textos, 2009, p. 23.

MARQUES, Marcos Osorio. Educação nas Ciências: os novos desafios. Revista Educação nas Ciências. Ijuí, RS: Ed. Unijuí, v.1, n¹, 2001, p.21-43.

MENDONÇA, Daniel de. O limite da normatividade na teoria política de Ernesto Laclau. Lua Nova, São Paulo, n. 91, p. 135-167, abr. 2014 . Disponível em <http://www.scielo.br/scielo.php?script=sci_arttext\&pid=S010264452014000100006\&lng=pt\&nrm=iso>. Acesso em 31 jul. 2019. http://dx.doi.org/10.1590/S0102-64452014000100006.

MOREIRA, Ildeu de Castro. A inclusão social e a popularização da ciência e tecnologia no Brasil. Inclusão Social, Brasília, v.1, n.2, 2006, p. 11-16.

MOUFFE, Chantal. La política democrática en la época de la postpolítica. Debates y Combates, 2011. 


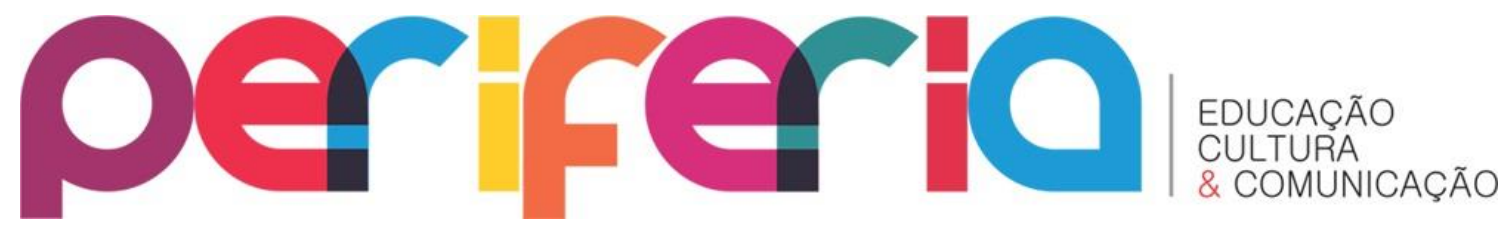

ISSN:1984-9540

DOI: 10.12957/periferia.2021.50074

PEREIRA, Guilherme. Produção discursiva sobre questões ambientais no currículo de licenciatura em geografia. 2014. Dissertação (Mestrado em Educação) - Faculdade de Educação da Baixada Fluminense, UERJ, Duque de Caxias, 2014.

ROCHEL DE CAMARGO, J. R. K. Lá vamos nós outra vez: a reemergência do ativismo antivacina na Internet. Cad. Saúde Pública, Rio de Janeiro, v. 36, supl. 2, e00037620, 2020 .

SADER, Emir. "Para outras democracias". In: SANTOS, B. S. (org.). Democratizar a democracia - Os caminhos da democracia participativa. Porto: Afrontamento, 2003. p. 138.

SANTOS, Boaventura de Sousa. Um discurso sobre as ciências. 16. ed. Porto: B. Sousa Santos e Edições Afrontamento, 2010. 59p.

SALAS, Javier. Você não pode convencer um terraplanista e isso deveria te preocupar. El País, São Paulo, 04 mar. 2019. Disponível em: <https://brasil.elpais.com/brasil/2019/02/27/ciencia/1551266455_220666.ht ml>. Acesso em: 12 set. 2019.

TIVIANE, Fernando Félix. BCI É DAQUI OU ESTÁ AQUI?: Uma etnografia da recepção da publicidade do Banco Comercial e de Investimento $(\mathrm{BCl})$ veiculada nas televisões, rádios e nos outdoors em Moçambique. 2015. 109 f. p. 37. Dissertação (Mestrado) - Curso de Programa de Pós-graduação em Antropologia Social, Instituto de Filosofia e Ciências Humanas, Ufrgs, Porto Alegre, 2015. Disponível em:

$<$ https://www.lume.ufrgs.br/bitstream/handle/10183/117543/000966279.pdf ?sequence=1>. Acesso em: 31 jul. 2019.

VASCONCELLOS-SILVA, P. R.; CASTIEL, L. David; GRIEP, R. H. A sociedade de risco midiatizada, o movimento antivacinação e o risco do autismo. Ciênc. saúde coletiva, Rio de Janeiro, v. 20, n. 2, p. 607-616, Feb. 2015.

WORLD HEALTH ORGANIZATION. Ten threats to global health in 2019. Disponível em: <https://www. who.int/news-room/feature-stories/tenthreats-to-global-health-in-2019>. Acesso em: 07/04/2020.

ZAMBONI, Lilian Márcia Simões. Cientistas, Jornalistas e a Divulgação Científica: subjetividade e heterogeneidade no discurso da divulgação científica. Campinas, SP: Ed. Autores associados, 2001. p. 50. 